\title{
VEINTICINCO AÑOS DE ESTADO AUTONÓMICO
}

\author{
AGUSTÍN RUIZ ROBLEDO \\ ProfesorTitular de Derecho Constitucional \\ Universidad de Granada
}




\section{SUMARIO}

I. INTROdUCCIÓN. II. El MOMENTO fundacional: LA CONSTITUCIÓN dE 1978. III. LA CONFIGURACIÓN DEL MODELO: HACIA LA HOMOGENEIDAD. IV. LA CONSOLIDACIÓN DEL MODELO. V. LA FORMA DE ESTADO REALMENTE EXISTENTE. VI. MÍNIMO BALANCE Y PROYECCIÓN PARA EL FUTURO. VII. NOTA BIBLIOGRÁFICA. 


\title{
VEINTICINCO AÑOS DE ESTADO AUTONÓMICO
}

\author{
POR \\ AGUSTÍN RUIZ ROBLEDO \\ Profesor Titular de Derecho Constitucional \\ Universidad de Granada
}

"Te digo, con franqueza, que el sistema español ha sido bueno, muy bueno. Hay mucho que aprender de vosotros».

(Antonio La Pergola, ADCP, núm. 14, 2002, pág. 33)

"El balance del Estado autonómico en estos veintitrés años es bueno, muy buenon.

(Jordi PUJOL en el programa La noche abierta, de TVE,

8 de julio de 2003)

\section{INTRODUCCIÓN}

Las frases del tenor de las pronunciadas por Antonio La Pergola y Jordi Pujol no son nada excepcionales ni en el mundo académico ni en el político. Es más, la mayoría de los ciudadanos son de parecida opinión: el $67,4 \%$ de los españoles considera que en general la creación y desarrollo de las Comunidades Autónomas ha sido para España algo más bien positivo, mientras que sólo el $12,6 \%$ piensa que ha sido más bien negativo. 
Sin embargo, debajo de esos juicios globales positivos hay, en ambos mundos, el académico y el político, tantas matizaciones, tantas llamadas a continuar el formidable despliegue del Estado autonómico, tantas afirmaciones sobre la necesidad de cerrar el sistema para no convertir al Estado en un cascarón vacío, tantas propuestas de reforma y adaptación a los nuevos retos del siglo XXI, tantas defensas de la validez de los Estatutos y de lo innecesario que es su reforma, tantas disputas sobre modelos de Estado o sobre cuál partido tiene modelo y cuál pone en riesgo la unidad de España, que si uno cierra los ojos y deja vagar libremente su pensamiento, la idea del éxito del Estado autonómico le parecerá una especie de ensoñación colectiva, un mantra políticamente correcto que los españoles nos repetimos unos a otros para no tener que reconocer que Ortega y Gasset tenía toda la razón del mundo cuando decía que el "problema regional» era insoluble y que había que acostumbrase a conllevarlo. No se dedican miles de páginas a completar un éxito, ni cientos de discusiones políticas a perfeccionar un acierto. Actualizando las palabras de Emil Cioran sobre la inadecuación de España al mundo moderno, se podría decir que la prueba más radical del fracaso del Estado autonómico consiste en que es imposible hablar con un español mínimamente politizado sin que el tema gire hacia el Estado autonómico, «universo cerrado, tema de su lirismo y de sus reflexiones, provincia absoluta, fuera del mundo".

Pero mejor será que abramos los ojos, miremos alrededor para observar una sociedad democrática que goza de un buen nivel de desarrollo económico y social, integrada en la Unión Europea, donde la convivencia política es aceptable, sin riesgos de golpes, ni sublevaciones. Muy lejos quedan ya los turbulentos años treinta y la dictadura de las décadas siguientes. Los veinticinco años de vigencia de la Constitución han sido extraordinariamente positivos; hoy la democracia está enraizada en España y el Estado se ha descentralizado en muy buena medida, como demuestra la comparación del gasto público entre 1981 y 2002: mientras en el primero la distribución del gasto público era un $87 \%$ del Estado, 3\% de las Comunidades Autónomas y $10 \%$ de los Entes locales, en el 2002 los nuevos porcentajes no tienen nada que envidiar al de los Estados federales: $48 \%$, Estado, 36\% Comunidades Autónomas, $16 \%$ Entes locales.

Por eso, quizás podríamos decir que el problema regional no se ha resuelto, pero lo estamos conllevando estupendamente. Huyamos de los juicios apocalípticos y pensemos en las luces y las sombras de este cuarto de siglo para poder seguir conviviendo, aunque sea admitiendo modestamente que los temas instrumentales, de organización territorial del poder político, siempre van a tener un peso en la políti- 
ca española muy superior al que tienen en otros Estados democráticos. Incluso, quizá si partimos de este punto modesto algún día nos encontremos, para nuestra sorpresa, que ya no hablamos recurrentemente de la articulación territorial de España. Entonces, aplicando el test de Cioran, podremos decir con satisfacción que el Estado autonómico es un completo éxito. Pero me parece que me estoy precipitando en mis conclusiones y mejor será que empiece por el principio, por el origen del Estado Autonómico.

\section{EL MOMENTO FUNDACIONAL: LA CONSTITUCIÓN DE 1978}

El final del franquismo cumplió milimétricamente el conocido axioma de la Ciencia Política sobre la ineficacia de las dictaduras para resolver los "problemas" en los que se basan para justificar la destrucción de la democracia: si uno de los motivos alegados recurrentemente para el golpe de Estado de julio de 1936 fue acabar con el separatismo y garantizar la unidad de España, no cabe duda de que cuarenta años después el gran problema constitucional de la democracia recuperada no era otro más que la forma de Estado, la distribución territorial del poder político, mientras que cuestiones tan polémicas en la década de 1930 como el modelo económico, la Jefatura del Estado, el papel de la Iglesia y del Ejército, pasaron a un segundo término. Todas las fuerzas políticas que obtuvieron representación parlamentaria el 15 de junio de 1977 tenían plena conciencia de que la Constitución territorial era el gran reto que debian afrontar, el "tema crucial» (Sánchez Agesta) del que dependia que la Constitución "acabe funcionando o no" (Solé Tura) y por el que serían «juzgados por la Historia" (Fraga). No está de más señalar, porque a veces de puro sabido casi se termina olvidando, que entre esas fuerzas políticas se encontraban dos nacionalistas periféricas, con amplio respaldo popular en sus respectivos territorios: el Partido Nacionalista Vasco y Convergencia i Unio, acompañadas de otras de menor relevancia (Euskadiko Ezkerra, Esquerra Republicana de Cataluña). Ellas eran la manifestación evidente de la necesidad de afrontar una reestructuración de la forma de Estado y también la prueba de que esa reestructuración tenía que tener como objetivo, en primer lugar, la integración de Cataluña y en País Vasco en España.

El 1 de agosto de 1977 la Ponencia constitucional comenzó sus trabajos. Mientras ésta elaboraba el anteproyecto de Constitución, el Gobierno inició un proceso paralelo de descentralización "provisional» 
del Estado, negociado con los principales partidos de la oposición. Así, mediante el Real Decreto-Ley 41/1977, de 29 de septiembre, se restableció la Generalidad catalana y el Real Decreto-Ley 1/1978, de 4 de enero creó el Consejo General Vasco. Aunque ambas normas jurídicas fueron pactadas y suponían un primer paso en el reconocimiento del autogobierno de estas nacionalidades, había una diferencia sutil entre ellas: mientras en el primer caso se trataba de entroncar con la legitimidad histórica catalana, el Consejo General Vasco era un organismo de nuevo cuño. La voluntad del Gobierno de reinstaurar las instituciones republicanas había sido en ambos casos similar, pero mientras se produjo el acuerdo con todas las fuerzas políticas catalanas para la vuelta de Josep Tarradellas - con su famoso "ja soc aquí» del 23 de octubre - no fue posible un pacto con el PNV para que Jesús M0 de Leizaola protagonizara un retorno similar y sólo se pudo lograr que aceptara la creación del Consejo. Este tipo de acuerdos logrados después de un primer desencuentro (que no sé si deberían llamarse acuerdos en la segunda vuelta, acuerdo de mínimos, medio acuerdos o algo similar) marcarán ya permanentemente la tónica de las relaciones entre el Gobierno central y el partido mayoritario del País Vasco. Sin olvidar el ominoso telón de fondo del recurrente problema del terrorismo de ETA y el acoso al que están sometidos muchos demócratas vascos.

Después de la aprobación de estos dos Decretos-Leyes, el Gobierno se planteó un dilema que, de una forma u otra, volvería a surgir recurrentemente en la configuración del Estado autonómico: si establecer o no otros regímenes "preautonómicos" similares en el resto del territorio nacional. A favor de no hacerlo, limitandose a los dos ya creados, se podría alegar una buena batería de argumentos: la inconveniencia de interferir en las decisiones de los constituyentes, la experiencia italiana al final de la II Guerra Mundial de adelantar únicamente las autonomías especiales, la falta de legitimidad histórica en la que apoyar esos nuevos regímenes, la ausencia en las Cortes de partidos nacionalistas de otros territorios, etc. Pero en sentido contrario, también había un buen número de razones, empezando por la voluntad política y social: por toda España habían surgido "Asambleas de Parlamentarios», formadas por los diputados y senadores electos el 15 de junio (la primera, la de los vascos, el 19 de junio), que reclamaban sus respectivas preautonomías, algunas de ellas con un indudable respaldo popular detrás, como el caso de Andalucía, donde el 4 de diciembre de 1977 se celebraron manifestaciones en favor del autogobierno que reunieron a más de un millón de personas. Por no hablar del «café para todos" como táctica para tranquilizar a los mandos militares y 
otros "poderes fácticos" preocupados por las reivindicaciones autonómicas de Cataluña y Euskadi.

Así, la opinión de José Clavero Arévalo, ministro para las regiones, terminó imponiéndose en el seno del Gobierno, que extendió las preautonomías por toda España a lo largo de 1978. El último de los once Decretos-Leyes que aprobó el Gobierno, de acuerdo con la respectiva Asamblea de Parlamentarios, lo fue el mismo día que las Cámaras aprobaban el texto definitivo del proyecto de Constitución: el Real Decreto-Ley 32/1978, de 31 de octubre, sobre Régimen Preautonómico de la Región de Castilla-La Mancha. Si algunas provincias se quedaron sin preautonomía (Navarra, León, Cantabria, La Rioja y Madrid) fue por las dudas sobre su ubicación en el mapa autonómico, no por falta de voluntad para generalizar el modelo. Por mucho que cada uno de los trece Decretos-Leyes tomará la prevención de señalar que «en nada prejuzgaba el contenido de la futura Constitución", lo cierto es que la decisión de crear estos regimenes influyó tanto en la elaboración del texto constitucional y -más importante- en su desarrollo posterior. Volveré sobre este punto que me parece de gran importancia para entender el desarrollo del Estado autonómico.

Al día siguiente de la aprobación del Decreto-Ley de la preautonomía vasca, el 5 de enero de 1978, publicaba el Boletín Oficial de las Cortes el Anteproyecto de Constitución elaborado por los siete miembros de la Ponencia Constitucional, así como los votos particulares. El anteproyecto recibió una auténtica avalancha de enmiendas que en el punto que a nosotros interesa ahora, la configuración territorial del poder político, iban en todas las direcciones imaginables, desde las preocupadas por resaltar la unidad de España - que se consideraba en peligro al haber recogido en el artículo dos el término "nacionalidades" - hasta las movidas por el deseo de proclamar una confederación. La Constitución territorial que diseñaba el Anteproyecto retomaba la idea republicana del principio dispositivo, para soslayar el complicado tema de diseñar un mapa autonómico y era, en términos generales, claro, coherente y bastante autonomista, no en balde - según indican las actas de las sesiones - los ponentes realizaron su trabajo partiendo de un texto presentado por Miguel Roca Junyent. Sin embargo, muchas cosas cambiaron en el texto que esa misma ponencia redactó como Informe en abril de 1978, hasta el punto que se puede decir que se rescribió de nuevo la Constitución territorial, tanto es así que el texto del que partieron los ponentes en esta segunda vuelta para debatir el Título VIII no fue el del Anteproyecto que ellos mismos habian redactado, sino uno nuevo que presentó UCD. Si en el Anteproyecto aceptaba claramente el derecho a la autonomía de las 
nacionalidades y regiones, estableciendo un procedimiento único relativamente sencillo de transitar para constituir "Territorios Autónomos", el Informe y los siguientes textos marcarían una línea distinta, produciendo un texto confuso y problemático, con cinco diferencias dignas de resaltarse en comparación con el Anteproyecto:

a) La introducción de cautelas frente a la autonomía. Así por, ejemplo, se termina dando una barroca y reiterativa redacción del artículo dos para garantizar la «indisoluble unidad de la Nación españolan, se reivindica el papel del Estado como garante de la solidaridad proclamada en el artículo 2 (art. 138.1) y se prohíbe la federación entre Comunidades (art. 145).

b) La gran variedad de iter autonómicos, con dos modelos básicos: el procedimiento ordinario del artículo 146 (o más exactamente del 146 en relación con la disposición transitoria primera, que permitía a los entes preatonómicos sustituir la iniciativa de las diputaciones provinciales) y el especial para Cataluña, el País Vasco y Galicia (disposición transitoria segunda). El procedimiento pensado en el Anteproyecto se concibe en el texto constitucional definitivo como un procedimiento excepcional, repleto de cautelas para verificar la voluntad autonomista, en especial se introduce un referéndum de ratificación de la iniciativa autonómica con un quórum difícil de alcanzar: tiene que ser aprobado por la mayoría absoluta del censo electoral de cada provincia.

c) El Anteproyecto diseñaba un Estatuto elaborado por un procedimiento paritario Asamblea-Congreso, con un modelo institucional Asamblea-Consejo Gobierno-Presidente y una sola forma de fijar las competencias (por atribución de los Estatutos respetando el techo del art. 149). Este esquema sólo se acaba estableciendo expresamente para las tres Comunidades Autónomas que podían constituirse por el procedimiento especial de la Disposición Transitoria Segunda y para las que lo hicieran transitando por el 151. Curiosamente, la autonomía de estas Comunidades salió ampliada en el iter constitucional: se calificó su Asamblea de "Legislativa", se señaló que en ellas habría un Tribunal Superior de Justicia, se matizaron algunas competencias estatales que serían "sin perjuicio" de su ejecución autonómica, etc. 
d) Las rebajas autonómicas se concentraron en el resto de Estatutos: se elaborarían por una Asamblea de Parlamentarios, pero en las Cortes se tramitarían por el procedimiento ordinario de la ley orgánica, no se les garantizaba ninguna Asamblea Legislativa elegida por sufragio universal y se fijaba un catálogo de materias inferior a las de las otras Comunidades, en las que para nada se hacía referencia a que podrían ejercer sobre ellas competencias legislativas (art. 148).

e) El Senado del Anteproyecto era un Senado mixto, compuesto en parte por los urepresentantes de los distintosTerritorios Autónomos que integran Españan y en parte por un máximo de veinte notables elegidos por el Congreso. Sin embargo, el Senado que se acabó configurando en el artículo 60 es un Senado - si se me permite la expresión- esquizofrénico: se declara que es la cámara "de representación territorial» y sin embargo, la gran mayoría de sus miembros es elegida por un sistema ajeno a las Comunidades, como son las provincias y las islas (208 senadores), mientras que sólo una minoría se elige atendiendo expresamente a su representación autonómica (51 senadores en esta VII Legislatura).

Llegados a este punto, me parece que hay que detenerse en el tenor literal del artículo 69.5 de la Constitución: "La designación corresponderá a la Asamblea legislativa o, en su defecto, al órgano colegiado superior de la Comunidad Autónoma». ¿En qué estaban pensando los miembros de la Comisión Mixta Congreso-Senado cuando introdujeron ese párrafo? Evidentemente, en dos tipos de Comunidades: unas con Asamblea Legislativa, capaces de aprobar leyes equiparables a las estatales, $y$ otras administrativas, potentes mancomunidades de diputaciones, pero sin el rasgo esencial de la autonomía política que es la capacidad legislativa. Todas las diferencias entre el Anteproyecto $y$ el texto final cotejadas antes se entienden ahora desde esta -en definición de Tomás y Valiente- "concepción dual» de la autonomía. Lo mismo se puede decir de la negativa a constitucionalizar expresamente la capacidad legislativa de todas las Comunidades, que se llevó hasta el extremo de rechazar una enmienda en ese sentido de Fraga Iribarne, tan poco sospechoso de excesos autonomistas -en aquella época- que fue el más pertinaz adversario de consagrar el término "nacionalidades".

Así las cosas, creo que la ampliamente admitida tesis del compromiso dilatorio o compromiso apócrifo - según el conocido térmi- 
no de Schmitt - que dio lugar al principio de voluntariedad en la formación de las Comunidades debe ser matizada: es verdad que la Constitución española desconstitucionaliza la forma de Estado permitiendo que el legislador ordinario elija entre diversas formas de articulación territorial del poder político, incluida el Estado unitario. Sin embargo, esta última opción estaba completamente descartada en la práctica y nadie dudaba de que los órganos preautonómicos de Cataluña, el País Vasco y Galicia (Galeusca, por usar la vieja expresión republicana) adoptarían rápidamente los acuerdos pertinentes para elaborar su Estatuto por el procedimiento del artículo 151 y constituir Comunidades Autónomas de primer grado. Por tanto, la ambigüedad real y verdadera del Título VIII giraba exclusivamente sobre cómo se organizaría el resto de España (RES).Y el motivo, como me parece que ha quedado claro en los párrafos anteriores, no podía ser otro más que la intención del constituyente (o mejor la mayoría de los constituyentes, pues evidentemente la voluntad de un grupo plural dista mucho de ser única) de desarrollar un Estado con dos tipos de autonomía o, diciendolo con lenguaje actual, un federalismo asimétrico.

La ambigüedad y truculencia delTítulo VIII no fue - como a veces se señala - el producto de un compromiso entre tres grupos distintos, los partidarios del Estado unitario descentralizado, los partidarios del Estado federal homogéneo y los nacionalistas periféricos preocupados únicamente por sus territorios. No hubo un acuerdo para dar cabida a estas tres opciones para elegir entre ellas en un momento posterior porque la opción de la autonomía política amplia para Galeusca estaba claramente configurada en la Constitución. Con un poco menos de contundencia, pero también con claridad, la Constitución de 1978 (esto es el texto que aprobaron las Cortes en octubre de 1978 y se sometió a referéndum el 5 de diciembre, no la Constitución efectivamente vigente hoy, aunque el texto sea el mismol establecía una amplia autonomía administrativa, sin capacidad legislativa, para la mayoría de las regiones que formaban el RES.

Interpretar el silencio constitucional sobre este punto como una remisión deliberada que hacia el constituyente al legislador ordinario para que eligiera entre dos posibilidades, no sólo casa mal con la lectura de los debates constituyentes y con las opiniones de los propios participantes (sobre todo las realizadas en los momentos posteriores, como las de Clavero y Attard, siempre más creibles que las pronunciadas muchos años después, cuando la memoria ha tenido tiempo de reconstruir lo que entonces se hizo); sino que es completamente absurda desde la más pura interpretación técnica: ¿tiene la mínima lógica establecer un referéndum de ratificación autonómica con un quórum 
difícilísimo de alcanzar para llegar cinco años antes al punto al que acabarán llegando todas las demás? O peor: a uno inferior, porque las autonomías de via lenta terminarian sobrepasando a las rápidas y disfrutando de una mayor autonomía al poder regular libremente sus instituciones, sin el corsé constitucional del artículo 152. Para evitar este absurdo (más que una paradoja), la única solución es -como muy bien señaló Pérez Royo en su momento - considerar que los artículos 147 y 152 eran alternativos ${ }^{1}$.

Por eso, en mi opinión, el silencio sobre la estructura institucional de las Comunidades Autónomas de segundo grado no es producto de una supuesta indecisión del constituyente, ni de su voluntad de ganar tiempo para seguir discutiendo la forma de Estado, sino de un compromiso implícito: la mayoría de los constituyentes fueron deliberadamente ambiguos sobre las Comunidades ordinarias o de segundo grado para evitar que la Constitución perdiera apoyo popular y político. El Título VIII se concibió, primeramente, para satisfacer las demandas de autogobierno del País Vasco y Cataluña; para resolver un problema, la integración de estos territorios en España, que de una forma u otra ha estado siempre presente en la formación del Estado de Derecho en España, recorriendo toda la Historia contemporánea española, por no remontarnos a otros tiempos anteriores.

El compromiso apócrifo de los constituyentes sobre el Estado autonómico se restringe así a un único punto: a la introducción del artículo 151 que permitía a algunos territorios del RES equipararse a las nacionalidades históricas y dotarse de una Asamblea Legislativa. Y es un compromiso que se produce no tanto entre distintas fuerzas politicas, especialmente las dos de mayor implantación nacional (UCD y el PSOE), sino dentro de los propios partidos, pues las discrepancias en este punto eran más bien transversales, por líneas internas dentro de los grandes partidos. En el caso de UCD esta división fue patente: Clavero, autor material del texto del artículo 151, estaba pensando en que Andalucía debería equipararse a las nacionalidades históricas. Por el contrario, otros muchos miembros de la UCD pensaban $-y$ muy pronto lo harían expreso- que ninguna región debería alcanzar el status de Comunidad de primer grado. Es muy posible que en el interior del PSOE también hubiera opiniones asi de encontradas, pues si no es

1 Insisto en la idea de la Constitución aprobada en 1978; luego, y a la vista de los Estatutos del 147 con las mismas instituciones que el 152, no cabe más opinión que mantener, con el TC, que el 152 es una lex specialis en relación con 
incomprensible la facilidad con que admitieron las líneas generales del Título VIII, muy distante del modelo federal que habían expuesto en su programa ${ }^{2}$, aunque no se manifestaron con la claridad que en el caso de la UCD. Los acontecimientos posteriores, incluida su derrota electoral en las elecciones generales de 1979 y su retroceso en Andalucía, gracias al éxito andalucista ( 5 diputados), impidió que en el seno del PSOE pudiera cristalizar una división similar a la que le sucedió al partido centrista, optando todo el partido por apoyar a Andalucía en su lucha por la autonomía plena. Pero eso es ya otro capítulo.

\section{LA CONFIGURACIÓN DEL MODELO: HACIA LA HOMOGENEIDAD}

Fuera por un compromiso apócrifo general de los constituyentes, fuera por uno parcial limitado al artículo 151 y una calculada ambigüedad en la redacción delTítulo VIII para no perder apoyos sociales, lo cierto es que tras la aprobación de la Constitución llegaba el momento de activar los mecanismos constitucionales para desplegar el Estado autonómico. La hoja de ruta - por usar un anacronismo evidentepara Cataluña y el País Vasco se cumplió milimétricamente y a gran velocidad, tanta que en la madrugada del 22 de diciembre de 1978, tres dias antes de la ratificación por las Cortes de la Constitución, aprobaban los parlamentarios vascos con una sola abstención (un diputado de UCD disidente) el proyecto de su Estatuto de Autonomía y el 29 de diciembre, el mismo día de la entrada en vigor de la Constitución, lo estaban presentando en el registro del Congreso. Los parlamentarios catalanes no se quedaron muy atrás (exactamente una hora: mientras el proyecto vasco se registró a las 19.12 , el catalán lo fue a las 20.23). El proceso autonómico posterior - retrasado unos meses por

2 Piénsese, por ejemplo, que no presentó ningún voto particular sobre el Título VIII, mientras que sí lo hizo sobre la Corona. También es muy ilustrativa la retirada de Peces Barba de la Ponencia constitucional el 6 de marzo de 1978, el día en que se iba a debatir elTitulo VIII: no la motivó su más que acertada opinión sobre lo incorrecto de tomar como base de discusión del Informe un texto que presentó UCD, al margen de las propias enmiendas de UCD al Anteproyecto (se limitó a hacer constar en actas sus "dudas" jurídicas), ni el propio contenido de este nuevo texto (con la ya consabida concepción dual de la autonomía), sino en la nueva redacción del art. 27, el derecho a la educación, que fue a su juicio una «ruptura del consenso" (Acta del 6 de marzo de 1978 de la Ponencia Constitucional, publicada por la RCG, núm. 2, segundo cuatrimestre, 1984, pág. 337 y ss). 
las elecciones generales de 1 de marzo - siguió también un ritmo vertiginoso, de tal forma que sus respectivos referéndums se celebraron el 25 de octubre y la publicación simultánea de ambos Estatutos en el BOE se hizo el 22 de diciembre de 1979.

Sobre ambos textos jurídicos se han escrito miles de páginas, pero para el propósito de este trabajo creo que es suficiente con destacar la distinta posición de las fuerzas políticas en una y otra nacionalidad: los nacionalistas catalanes votaron favorablemente tanto la Constitución como su Estatuto, el cual recibió incluso el sí de Esquerra Republicana, que había votado en contra de la Lex legum; sin embargo, el PNV se abstuvo en la Constitución y no concibió el Estatuto como un do ut des, sino como un mínimo que no le impedía seguir aspirando a un grado mayor de autogobierno; por su parte los nacionalistas extremistas de Herri Batasuna - fundada en abril de 1978- se opusieron tanto a la Constitución como al Estatuto. La gran presión de esta fuerza política difícilmente puede ser exagerada porque - además de su refuerzo terrorista - tenían un gran respaldo social detrás, tanto que lograron más de 172.000 votos y tres diputados en las elecciones al Congreso del 1 de marzo. En las locales del 3 de abril, incluso superaron al PSOE y se convirtieron en la segunda fuerza vasca: EI PNV fue el más votado con 360.000 votos, Herri Batasuna obtuvo 223.146, el PSOE 195.175 y UCD 180.980. ETA no dejó de asesinar y atacar la democracia, incluido el grave atentado que sufrió Gabriel Cisneros, antiguo ponente constitucional, el 3 de julio de 1979.

Pero dejemos a los vascos y a los catalanes preparando sus elecciones autonómicas de marzo de 1980 (con algunas actuaciones tan espectaculares como el abandono de las Cortes Generales en enero por parte del PNV para reclamar mayores transferencias al Consejo General Vasco) y vayamos a Galicia y al RES. Los parlamentarios gallegos miembros de las Cortes Constituyentes no actuaron con la misma rapidez que catalanes y vascos - recuerdese que todos ellos pertenecían a partidos estatales - y fueron los nuevos parlamentarios elegidos en las elecciones generales del 1 de marzo de 1979 los que elaboraron el proyecto de Estatuto gallego, que se presentó en las Cortes en junio de 1979. Su tramitación fue mucho más lenta que la de los catalanes y vascos pues aunque fue aprobado el 22 de noviembre de 1979 por la Comisión Constitucional del Congreso y la Delegación de la Asamblea Gallega únicamente votó a favor la UCD (y la ausencia de PNV, CiU y Coalición Democrática), mientras que lo hizo en contra toda la izquierda (socialistas, comunistas y andalucistas), que consideraba que la inclusión de una disposición transitoria para que una ley estatal delimitara las competencias autonómicas era una rebaja sustancial la 
autonomía gallega. Una nueva votación de la Comisión Constitucional el 29 de octubre de 1980 recuperó el consenso, justo en la misma época en que se desbloqueaba la situación andaluza y con una solución similar: a favor de la tesis autonomista. No hubo ya problemas - al margen de la baja participación en el referéndum estatutario del 21 de diciembre de 1980 - para continuar el iter autonómico y formar una Comunidad Autónoma de nivel similar al catalán.

Precisamente, la configuración actual del Estado autonómico - tan distinta de la división entre autonomías políticas y administrativas prevista implícitamente en la Constitución - se debió en buena medida al desarrollo del proceso autonómico andaluz pues su desenlace final hizo que fuera completamente imposible, desde el punto de vista político, impedir que primero Valencia, Canarias, Navarra y todas las demás, después, lograran una autonomía política tendencialmente igual, $o$ al menos homogénea, al de las nacionalidades históricas. Los primeros pasos del largo y complicado procedimiento del artículo 151 los comenzó a dar Andalucía en la misma época en que Cataluña y Euskadi comenzaban el suave y fácil proceso de la disposición transitoria segunda: el 5 de diciembre de 1978 once partidos andaluces - desde AP hasta la extrema izquierda - firmaron el Pacto de Antequera que les propuso el Presidente de la Junta Preautonómica, Plácido Fernández Viagas, para conseguir la autonomía plena. Tras las elecciones generales de marzo de 1979, todos los partidos cumplieron sus compromisos y en agosto de 1979 ya se habían obtenido los acuerdos favorables de las ocho diputaciones y del $95 \%$ de los municipios, superando así el quórum institucional del 151. Para afrontar el quórum social hubo que esperar hasta febrero de 1980, y hacerlo contando con la defección clara de UCD y AP, que recomendaron la abstención, con las condiciones restrictivas de la Ley Orgánica de Regulación de Modalidades del Referéndum (LORMR) y con toda clase de pequeñas argucias legales del Gobierno para evitar la victoria del sí. El resultado del referéndum fue una victoria política para sus defensores (más de dos millones y medio de votos, el $55 \%$ del censo andaluz), sin embargo fue una derrota jurídica porque no se superó la mayoría absoluta del censo en Almería, donde el sí alcanzó únicamente el $44 \%$.

Pero esa victoria política se acabó transformando en una victoria jurídica cuando, tras un fuerte enfrentamiento a lo largo de todo 1980, el Gobierno terminó aceptando en septiembre modificar la LORMR para "sustituir" la iniciativa autonómica y permitir que se redactase el Estatuto andaluz por el procedimiento pactado del 151.2. Evidentemente, si Andalucía lograba un Estatuto con Asamblea Legis- 
lativa no de una forma constitucional indubitada sino con la generosa ayuda del legislador, era completamente disparatado intentar impedir que Navarra (cuya Diputación Foral tenía preparado desde marzo de 1979 un proyecto de Amejoramiento del Fuero) tuviera también Asamblea Legislativa. $Y$ otro tanto cabe decir de Canarias y Valencia, donde sus órganos preautonómicos habian aceptado de mala gana el iter ordinario. Con buen criterio, y ante lo imparable de este efecto cascada, el Gobierno de UCD y el PSOE acordaron el 31 de julio de 1981 generalizar con orden, concierto y financiación adecuada el modelo de autonomía política para todo el territorio que aquí vengo llamando el RES. En este punto los pactos autonómicos fueron, sin duda, una convención constitucional pues sustituyeron el primitivo diseño constitucional de autonomías de primera, políticas, y de segunda, administrativas por la distinción entre autonomías de vía lenta y autonomías de vía rápida. Por esa misma categoría de convención constitucional de los «Acuerdos autonómicos firmados por el Gobierno de la nación y el Partido Socialista Obrero Español» - según su denominación oficial- me parece que no fue un acierto, antes al contrario, incluir en ellos la elaboración de una Ley de armonización y mucho menos, que no ìntervinieran en estos acuerdos de 1981 los demás participantes en el consenso constitucional, muy especialmente el PCE y CiU. No sé si en el verano de 1981 hubiera sido posible reeditar el consenso de 1978, incluso ampliarlo atrayendo al PNV, pero tampoco me consta que se intentara.

Una pequeña coda sobre este primer despliegue del Estado autonómico: en todo este proceso el papel de los entes preautonómicos fue determinante. En especial, el de la Junta de Andalucía pues sin ella los partidos políticos defensores de la autonomia plena no hubieran podido promover con la eficacia que lo hicieron ni el Pacto de Antequera, ni la iniciativa autonómica de los municipios, ni movilizar a la ciudadanía en el referéndum, ni mantener su bloqueo a cualquier solución jurídica que no pasara por el artículo 151.2. Tengo para mí que si no se hubiera creado la Junta, jamás se hubiera celebrado el referéndum y hoy no existiria el Parlamento de Andalucía ni los demás del RES. Por eso, el gran error estratégico de Suárez, Abril Martorell, Martín Villa y los demás partidarios de limitar la autonomía política a Cataluña y el País Vasco que les impidió alcanzar su objetivo no fue tanto lo mucho que tardaron en hacer expresa su posición, el 15 de enero de 1980 cuando el Comité Ejecutivo de UCD aprobó la «racionalización de las autonomías", sino cuando en enero de 1979 no usaron su mayoría en el Gobierno para limitar la creación de entes preautonómicos a Cataluña y el País Vasco. 


\section{LA CONSOLIDACIÓN DEL MODELO}

Después de la firma de los Acuerdos Autonómicos, la nueva Hoja de ruta empezó a aplicarse sin problemas y a un ritmo que no ha dejado de causar admiración en otros Estados con movimientos descentralizadores como Italia y Bélgica. A lo largo de 1981 y 1982 se celebraron las elecciones gallegas, se aprobó el Estatuto andaluz y se completó el mapa autonómico según lo pactado en julio: constitución de diecisiete Comunidades Autónomas, uso de la disposición adicional primera para la autonomía Navarra, ampliación de las competencias de Valencia y Canarias mediante leyes de transferencia específicas del artículo 150.2, elaboración de Ley orgánica de Armonización, etc. Incluso puede decirse que el plazo que se fijaron Joaquín Calvo Sotelo y Felipe González se cumplió: el último Estatuto, el de Castilla y León se aprobó en febrero de 2003 y la incorporación de Segovia a esa Comunidad se realizó el 1 de marzo, mediante la Ley Orgánica $5 / 1983$. Justo un mes después del plazo que se habían dado los dos líderes, el 1 de febrero de 1983. El 8 de mayo de 1983 se celebraron las primeras elecciones para las Asambleas Legislativas de estas trece Comunidades Autónomas.

El Estado autonómico homogéneo completaba así su primer escalón, la elección de los 18 poderes políticos territoriales españoles (17 parciales y uno general). Sin embargo, todavía faltaba mucho para su despliegue efectivo. Para empezar, era necesario que se pusieran en marcha las Comisiones mixtas del Gobierno estatal con cada uno de los autonómicos para transferirles funcionarios, bienes y servicios; después estaban la concreción del sistema de financiación, la aprobación de algunas leyes estatales necesarias para el ejercicio de ciertas competencias autonómicas (como la creación de las televisiones autonómicas), la precisión de los ámbitos estatal y autonómico mediante la aclaración de los conceptos del bloque de la constitucionalidad de bases, competencias exclusivas sin perjuicio, etc. En este punto, entró en escena un nuevo y extraordinario actor del Estado autonómico, el Tribunal Constitucional, al cual han acudido tanto los actores ordinarios - el Estado y las Comunidades - que se ha podido decir que tenemos un Estado jurisdiccional autonómico. Su más conocida intervención de esta primera época fue la STC 76/1983, caso recurso previo contra la LOAPA, en la que declaró inconstitucional este tipo de leyes de armonización preventivas, si bien interpretó de tan extensiva manera algunos de los títulos estatales del art. 149.1 que atribuyó por esta vía los instrumentos jurídicos que el legislador estatal se quería atribuir por la de la Ley de armonización. 
Después el Tribunal Constitucional ha tenido que pronunciarse en medio millar de ocasiones sobre el Estado autonómico, donde se ha puesto a prueba su capacidad para cumplir la labor de juez con la que fue concebido. Afortunadamente, su jurisprudencia goza de una auctoritas entre los especialistas similar a la de otros tribunales constitucionales de otros Estados compuestos, si bien desde el mundo politico, los partidos nacionalistas han criticado sus decisiones, llegando incluso a una descalificación global en la Declaración de Barcelona de 1998. Aunque me parece que exageran al calificar su jurisprudencia como claramente centralista, no les falta un punto de razón cuando consideran que podría mejorarse su composición: habría que buscar alguna fórmula para que las Comunidades Autónomas participaran en la designación de algunos magistrados. Argumentar que ya lo hacen por la vía indirecta de la elección de cuatro de sus miembros por el Senado ralla en el cinismo, porque en la práctica se ha tratado de una decisión que han tomado de común acuerdo los dirigentes de los dos grandes partidos, el PP y el PSOE, sin apenas dar una mínima opción de intervención no ya a los partidos nacionalistas, sino a los dirigentes regionales de sus partidos.

Pero en este punto me parece que el problema no radica tanto en la composición de un órgano jurisdiccional, como en el uso que hacen de él los partidos políticos, que someten sus controversias al veredicto del Tribunal Constitucional con una frecuencia inusual por otros lares. No me parece - a diferencia de lo que suele afirmarseque su activo papel en el Estado autonómico se deba a la complejidad del bloque de la constitucionalidad. Es verdad que es complejo, por no decir que a fuer de prolijo es confuso y ambiguo, pero la razón del papel del Tribunal Constitucional no reside primariamente ahí, sino en la incapacidad de los partidos para operar de común acuerdo dentro del Estado autonómico. Echese un vistazo a la legitimación activa y pasiva de los recursos de inconstitucionalidad y los conflictos de competencias y se compartirá esta afirmación: debajo de la legitimación formal de los distintos órganos legitimados para recurrir de las Comunidades Autónomas y del Estado se advertirá que el grueso de los recursos son las diferencias - muchas veces puramente políticasentre los partidos nacionalistas periféricos y el partido en el Gobierno central; después aparecerán las discrepancias entre el partido del Gobierno central y el partido de la oposición y en muy último lugar - que en mi particular y poco científico cálculo no debe sobrepasar el $3 \%$ de las impugnaciones- aparecerán las controversias entre el partido del Gobierno y un Gobierno autonómico controlado por el mismo partido. 
$Y$ esto nos lleva directamente a otro punto de este repaso a los veinticinco años del Estado autonómico: la poca presencia en nuestro país de una cultura federal que haga operativa la tan cita Bundestrue alemana, la lealtad federal, que en este asunto concreto debe manifestarse en la renuncia a continuar - recordando a Clausewitz- la lucha política mediante los medios jurídicos que ofrece el Tribunal Constitucional. Tras la intensa conflictividad de la década de 1980, los partidos parecen convencidos de la necesidad de abandonar esa vía e incluso modificaron la LOTC en 1999 para facilitar la negociación antes de recurrir definitivamente al juicio delTribunal Constitucional. La comparación, tosca si se quiere, con un buen partido de fútbol es inevitable: la intervención del árbitro del Estado autonómico -e intérprete supremo de la Constitución - debe ser excepcional pues, primero, son los actores del sistema político, dotados de la legitimidad democrática que les da las urnas, a los que les corresponde el protagonismo ordinario. $Y$ segundo, si el árbitro tiene que intervenir a menudo, antes o después el juego político acabará desleído en una continua discusión sobre las normas que lo rigen y alguien acabará acusando al árbitro de parcial:

\section{LA FORMA DE ESTADO REALMENTE EXISTENTE}

Los nuevos pactos autonómicos de 1992 entre el Gobierno del PSOE y el Partido Popular para incrementar las competencias de las Comunidades Autónomas de vía lenta han reforzado la pulsión homogénea del Estado autonómico mediante, primero, un proceso de reforma de los Estatutos de las Comunidades de segundo grado que ha llegado hasta el 2001, cuando se aprobó la última reforma del amejoramiento del fuero navarro y después, mediante el consiguiente traspaso de funcionarios y servicios, muy especialmente en las dos gran $\Rightarrow$ des competencias ejecutivas que retenía parcialmente el Estado: educación y sanidad. Este año 2001 fue muy importante para el Estado autonómico en cuanto se logró un pacto sobre el sistema de financiación, que había sido un motivo de profunda división en los años anteriores entre el PP y el PSOE. El pacto pretende terminar con las negociaciones quinquenales $y$ establece un sistema permanente. Merece la pena hacer un sumario repaso a la evolución del sistema de financiación ordinario, no son antes recordar que el País Vasco y Navarra siempre se han puesto de acuerdo - con más o menos dificultadcon el Estado para actualizar sus privilegiados sistemas de convenio. Las etapas del sistema ordinario son las siguientes: 
a) Período transitorio de 1981-1986 basado en el "coste efectivo" de los servicios transferidos. La idea central de este período era la de permitir que las Comunidades prestaran los servicios que les transfería el Estado con el mismo nivel de calidad que éste, para lo cual cuando el Estado les cedia funcionarios, locales y todos los bienes necesarios se calculaba una financiación aneja según ese coste, que se conseguía fundamentalmente por la cesión de impuestos estatales que realizó la Ley 30/1983 y un porcentaje anual de participación de cada Comunidad en los ingresos estatales (PIE).

b) Quinquenio 1987-1991 de establecimiento de un sistema basado en la participación en los ingresos del Estado. Garantizando que ninguna Comunidad perdería financiación con el nuevo sistema, se calculó un porcentaje de PIE fijo para todo el quinquenio partiendo de variables socioeconómicas y geográficas: coeficiente de población (el más relevante, con un peso aproximado del $95 \%$ ), nivel de renta, extensión del territorio, etc.

c) Quinquenio 1992-1996 de ajuste de ese sistema de financiación. EI PIE se desglosa en dos tramos: 1) uno general constituido por el rendimiento global del conjunto de los impuestos del Estado, excluidos los cedidos, cuyo reparto se hace según las tradicionales variables socioeconómicas y geográficas (que se corrigen levemente, incluyendo entre ellas el coeficiente de dispersión geográfica); 2) Otro tramo específico, el $15 \%$ de las cuotas líquidas del impuesto de la renta de las personas físicas (IRPF) ingresadas por los residentes en cada territorio.

d) Quinquenio 1997-2001 de un nuevo modelo de financiación basado en la corresponsabilidad fiscal. Se cedió parcialmente el IRPF a las Comunidades que aceptaron el nuevo sistema (todas menos Andalucía, Castilla-la Mancha y Extremadura, que se mantuvieron con el sistema del quinquenio anterior), atribuyendo cierta capacidad normativa a las Comunidades sobre ese tramo autonómico. Igualmente se les atribuyó una capacidad normativa, aunque muy condicionada, sobre los impuestos cedidos.

e) A partir de 2002: En julio de 2001 el Consejo de Política Fiscal y Financiera logró un acuerdo para ajustar el sistema del sistema de corresponsabilidad, incrementando las capacidades normativas autonómicas. Este nuevo sistema se fun- 
damenta (según declara la Ley $21 / 2001$, de 27 de diciembre, por la que se regulan las medidas fiscales y administrativas del nuevo sistema de financiación de las Comunidades Autónomas de régimen común y Ciudades con Estatuto de Autonomía) en los principios de generalidad, estabilidad, suficiencia, autonomia, solidaridad, coordinación, participación en la Agencia Estatal de Administración Tributaria y participación en los Tribunales EconómicoAdministrativos.

Para hacer efectivo el pacto de julio de 2001 se modificó la LOFCA ese mismo año y en el siguiente se aprobaron una batería de leyes complementarias (Ley 21/2001 de medidas fiscales complementarias, Ley 22/2001, de los Fondos de Compensación Interterritorial y las Leyes individuales de cesión de tributos). Igualmente otro paquete legislativo renovó el concierto vasco (Leyes 12 y 13/2002, LO 4/2002), y el convenio navarro (LO 10/2003, Ley 25/2003).

$\mathrm{Si}$ a todo este pacto fiscal se le unen otras medidas como la culminación de los traspasos de educación y sanidad a todas las Comunidades y la aprobación de leyes como la Ley 1/2002, de 21 de febrero, de Coordinación de las Competencias del Estado y las Comunidades Autónomas en materia de Defensa de la Competencia, uno está tentado de pensar que el Gobierno acierta cuando señala que se ha culminado el despliegue del Estado autonómico. Pero a poco que se mire el asunto se dará uno cuenta de que no es posible mantener esa opinión porque faltan una serie de temas pendientes que, aunque no tienen por qué cambiar la naturaleza del Estado autonómico y sus grandes líneas de desarrollo. Entre los flecos jurídicos de relevancia que todavía quedan merece la pena destacarse los siguientes:

a) Un cuarto de siglo después de su puesta en marcha, no se ha terminado todavía el despliegue del Estado autonómico en cuanto el ejercicio de las competencias ejecutivas autonómicas depende de un sistema de traspasos de servicios y funcionarios del Estado a las Comunidades Autónomas, mediante acuerdos en Comisiones mixtas bilaterales, que todavía no se ha cerrado en la mayoría de los casos debido a la diversidad de opiniones entre los representantes del Gobierno y el Ejecutivo autonómico respectivo.

b) Todavía se pueden mejorar los mecanismos de cooperación. Así, el propio Gobierno elaboró un proyecto de Ley de cooperación general, que duerme el sueño de los justos en el MAP y recientemente ha hecho pública su voluntad de consensuar una Ley de coordinación sanitaria. 
c) Se hace necesario un acuerdo en relación con la Unión Europea, ya que un buen número de Comunidades (todas las gobernadas por partidos distintos al del Gobierno central, pero también alguna de éste, como Galicia) no se siente satisfecho con su actual participación en la Unión Europea. El propio Partido Popular ha admitido - aunque alguien puede decir que con cinismo - esta necesidad de regular mejor la participación de las Comunidades Autónomas en la fase ascendente de la Unión Europa al rechazar en setiembre de 2003 la toma en consideración de una proposición de ley en este sentido remitida por el Parlamento de Cataluña.

d) Como tema estrella de los temas pendientes del Estado autonómico es la recurrente reforma del Senado, que el propio PP defendió claramente en 1996 y de una forma mucho más matizada (excluyendo la reforma expresa de la Constitución) en la nueva legislatura iniciada en el 2002.

Si desde lo que podemos llamar un punto de vista técnico se observan todavía flecos de gran importancia como para considerar cerrado el despliegue del Estado autonómico, desde el punto de vista político todavía existen menos motivos porque los partidos de la oposición discrepan de la postura del Gobierno. Así el PSOE, que recientemente ha presentado su proyecto de una «España plural» e lzquierda Unida que mantiene un "federalismo de libre adhesión". En otra esfera completamente distinta, está el proyecto de "libre asociación" del Lehendakari lbarretxe y un punto menos alejada de la órbita constitucional, está la propuesta de reforma del Estatuto catalán del Conseller en capArtur Más para dar cabida a las nuevas reivindicaciones nacionalistas de CiU.

Así las cosas, no es fácil determinar la forma de Estado actualmente imperante en España. En mi opinión, aunque es cierto que el Estado autonómico coincide en varios puntos esenciales con el Estado federal (garantía constitucional de la autonomía, resolución jurisdiccional de los conflictos, etc.) y que el nivel de autogobierno de las Comunidades es muy similar a la de muchos Estados miembros de Federaciones, me parece que sus diferencias jurídicas son lo suficientemente relevantes como para hacer factible su distinción. Pero su característica fundamental es más bien política, esa sensación de modelo inacabado, abierto, de continuo cambio que impera en la política española con relación a la distribución de competencias y que no responde a la teoría de Friedrich del federalismo como proceso. En el ámbito estrictamente jurídico cabe destacar, entre otras, las siguientes diferencias entre el Estado federal, y el autonómico: 
1. En el Estado federal los entes autónomos o son una realidad jurídica previa a la Constitución o nacen con ella, pues están expresamente recogidos en esa norma fundamental; por el contario, en el Estado autonómico, los entes autónomos no cobran existencia jurídica hasta que se aprueba por las Cortes Generales su Estatuto de Autonomía.

2. Los entes autónomos de un Estado federal participan tanto en la aprobación de la Constitución como en su reforma, mientras que en el autonómico no participaron en la elaboración de la Constitución y en su reforma sólo intervienen por la vía muy indirecta de los senadores autonómicos (que no están sometidos a ninguna instrucción de sus Comunidades), si bien tienen capacidad de iniciativa para la reforma constitucional. La misma falta de participación autonómica se produce en el procedimiento legislativo ordinario.

3. Los entes autónomos de un Estado federal tienen autonomía constitucional para elaborar su texto institucional básico (por lo demás, normalmente denominado "Constitución»), sin ningún tipo de intervención de los órganos generales del Estado, más allá del eventual control de constitucionalidad que pueda realizar los tribunales; por el contrario, en la elaboración de los Estatutos de Autonomía participan las Cortes Generales, incluso en el procedimiento especial del artículo 151, que como mucho puede calificarse - con la oposición de importantes autores - como un procedimiento pactado entre los representantes de una nacionalidad concreta y los de la nación española.

4. El principio dispositivo tiene importantes consecuencias sobre el orden competencial del Estado autonómico, desconocidas en el Estado federal, como es la declaración del derecho estatal como supletorio del autonómico. En este sentido, una diferencia relevante consiste en que las competencias del Estado central de una Federación se determinan en la propia Constitución y tienden a ser las mismas en todo el territorio, mientras que en el Estado autonómico esas competencias dependen indirectamente (vía cláusula de supletoriedad) de las que cada Estatuto atribuya a su Comunidad, lo que origina que las competencias estatales tiendan a no ser idénticas en todo el territorio nacional, lo que incluso se considera una característica positiva del sistema en 
cuanto permite que unas Comunidades tenga más competencias que otras (federalismo asimétrico).

5. El orden competencial gira en el Estado federal clásico sobre el concepto de materia y en el modelo germánico sobre el de función, distinguiendo entre la legislación y la ejecución; por su parte, el Estado autonómico emplea estas dos técnicas, pero le agrega otra que aunque no era desconocida no se había usado previamente con tanta asiduidad: la distinción en el interior de la función legislativa, diferenciando entre la legislación básica (competencia estatal) y la legislación complementaria (autonómica).

\section{MÍNIMO BALANCEY PROYECCIÓN PARA EL FUTURO}

"Sé que la poesía es indispensable pero ignoro para qué". No puedo dejar de citar la boutade de Jean Cocteau cuando pienso en la utilidad del Estado autonómico. Desde luego, si se estableció en la Constitución con el fin primordial de integrar los nacionalismos periféricos parece que ese objetivo, con la deriva soberanista del PNV, está lejos de lograrse. Si nos cargamos de optimismo podemos decir que no es la primera vez que parece que se va a crear una cesura insalvable y de pronto surge un rayo de esperanza. La propia Constitución no pudo integrar al PNV, que se abstuvo, y eso no impidió el pacto en la segunda vuelta constituyente, el Estatuto vasco, un éxito tan rotundo en su momento que fue vital para que la ETA político militar abandonara el terrorismo. Por el contrario, si el Estado autonómico tenía como fin secundario lograr una descentralización del RES, las encuestas de opinión señalan con claridad que la mayoría de sus habitantes -y mucho más la clase política - se encuentran satisfechos con el Estado autonómico y con su principio de homogeneidad.

La insatisfacción de las grandes fuerzas políticas del País Vasco y Cataluña con el Estado autonómico realmente existente nos lleva, como en el mito del eterno retorno, al mismo punto del que partió la construcción del Estado autonómico: la articulación de estas dos nacionalidades históricas sigue siendo un problema político de primera magnitud. Político y social, porque como ha recordado Javier Pérez Royo, la estructura territorial de un país es uno de los pocos temas constitucionales por los que la gente se mata. A nadie se le escapa que en la situación actual las dificultades para integrar satisfactoriamente a ambos nacionalismos son muy altas. $Y$ no tanto porque el Gobierno 
central del PP sea especialmente "nacionalista» español, sino por una dinámica interna del Estado autonómico: la lógica de la dualidad de autonomías políticas y autonomías administrativas con la que nació ha sido sustituida por un juego de lógicas antagónicas, la lógica del hecho diferencial que aplican los nacionalismos periféricos tradicionales y la lógica de la equiparación y la igualdad que reivindican las nacionalidades y regiones ordinarias. La nave del Estado debe fijar su rumbo con especial cuidado para sortear estas Escila y Caribdis que nos permitan llegar a la İtaca feliz de una España sin problemas de distribución territorial del poder político. Pero si ya lo logró hace veinticinco años en condiciones especialmente adversas ¿por qué negarnos la posibilidad de volver a conseguirlo ahora?

\section{NOTA BIBLIOGRÁFICA}

\section{Introducción}

Los datos sociológicos sobre la aceptación social de las autonomías lo he obtenido del Estudio núm. 2455, «Instituciones y autonomías» del CIS, septiembre de 2002.

La conocida posición de Ortega y Gasset sobre la imposibilidad de resolver definitivamente la articulación territorial de España la expuso en su Discurso antes las Cortes, de 13 de mayo de 1932 con motivo de la tramitación del Estatuto catalán. Merece la pena reproducir el grueso de su razonamiento:

"Pues bien, señores; yo sostengo que el problema catalán, como todos los parejos a él, que han existido y existen en otras naciones, es un problema que no se puede resolver, que sólo se puede conllevar, y al decir esto, conste que significo con ello, no sólo que los demás españoles tenemos que conllevarnos con los catalanes, sino que los catalanes también tienen que conllevarse con los demás españoles [...] porque frente a ese sentimiento de una Cataluña que no se siente española, existe el otro sentimiento de todos los demás españoles que sienten a Cataluña como un ingrediente y trozo esencial de España, de esa gran unidad histórica, de esa radical comunidad de destino, de esfuerzos, de penas, de ilusiones, de intereses, de esplendor y de miseria, a la cual tienen puesta todos esos españoles inexorablemente su emoción y su voluntad. Si el sentimiento de los unos es respetable, no lo es menos el de los otros, y como son dos tendencias perfectamente antagónicas, no comprendo que nadie, en sus cabales, logre creer que 
problema de tal condición puede ser resuelto de una vez para siempre. Pretenderlo sería la mayor insensatez, sería llevarlo al extremo del paroxismo, sería como multiplicarlo por su propia cifra; sería, en suma, hacerlo más insoluble que nunca».

[La opinión de Emile Cloran la he tomado de su Adiós a la filosofía (trad. de Fernando Savater), Alianza Editorial, 1980, pág. 31.]

\section{El momento fundacional: la Constitución de 1978}

Un buen ejemplo de la importancia que daban los constituyentes al Estado autonómico son los debates en la Comisión Constitucional del Congreso, de donde he tomado la idea de Fraga ( $D S C D$, núm. 59, de 5 de mayo, pág. 2043). También se pronunciaron en sentido similar Miguel Herrero Rodríguez de Miñón (pág. 2024), Santiago Carrillo (pág. 2038), Miquel Roca (pág.2053), etc. La cita de Jordi Solé Tura la he tomado del $D S C D$, núm. 91, de 16 de junio de 1978, pág. 3374. Dicho esto, llama la atención la breve referencia a la estructura territorial del poder político que le dedicó el ponente socialista Gregorio Peces Barba en su intervención del 5 de mayo (pág. 2029), que le hace decir a Jordi JARIA I MANZANO, que a diferencia del resto, el Grupo Socialista no "hizo explícita la constatación de la importancia de la distribución territorial del poder en la Constitución que se está elaborando" ["La forma del Estado en los debates constituyentes" en Miguel Ángel ApARICIO (dir.), La descentralización y el federalismo. Nuevos modelos de autonomía política, Cedecs, Barcelona, 1999, pág. 15]. Por mi parte, agrego que en la Minuta de la Ponencia Constitucional del 15 de noviembre de 1977 se puede leer una queja de Miquel Roca upor el desinterés de algunos miembros de la Ponencia sobre los debates de la Constitución y en especial sobre el tema de las Autonomías. A esta protesta se adhiere el señor Fraga, representante de AP" (Actas de la Ponencia Constitucional, RCG, núm. 2, segundo cuatrimestre, 1984, pág. 322). En esa misma revista se puede comprobar la decisión de tomar como base un texto de Roca para elaborar el Anteproyecto, a la que me refiero en el texto, está en el Acta del día 15 de noviembre de 1977, pág. 323.

El debate en el seno del Gobierno sobre "la conveniencia o no de continuar el proceso preautonómico» una vez aprobados los Decretos-Leyes vasco y catalán lo ha contado Clavero Arévalo, que como Ministro Adjunto para las regiones, fue uno de sus protagonistas y el más ferviente partidario de su generalización, cfr. Manuel CLAVERo ARÉVALO, España desde el centralismo a las autonomías, Planeta, Barcelo- 
na, 1983, págs. 5253. En este libro da cuenta, también, de como el grupo dirigente de UCD (llamado el "triciclo" porque estaba formado por algunos ministros, algunos parlamentarios $y$ algunos miembros de la ejecutiva del partido) era mayoritariamente partidario de constitucionalizar el sistema de autonomía plena sólo para Cataluña, el País Vasco y Galicia, mientra el resto serían simples mancomunidades, postura que no aceptó el Grupo Parlamentario. Como una fórmula de transacción entre ambas opiniones surgió el artículo 151, redactado por Clavero y Herrero de Miñón, si bien el quórum del referéndum que pensaron fue el del $40 \%$, elevado al $50 \%$ por la Ponencia Constitucional (op. cit. pág. 103 y ss).

La idea - no se si un tanto disparata - de llamar RES a lo que no ni Cataluña, ni el País Vasco la copio de la habitual expresión canadiense ROC, Rest of Canada.

La afirmación de la lógica dual del Estado autonómico de Francisco TOMÁS Y VALIENTE la tomo de su ASoberanía y autonomia en las Constituciones de 1931 y 1978", ahora en sus Obras Completas, CEC, Madrid, 1997, tomo III, pág. 2628. La defensa de la enmienda de Fraga Iribarne para garantizar que todas las Comunidades tuvieran Asamblea Legislativa evitando así la desaparición de "la pieza básica de toda autonomía" está en el $D S C D$, núm. 88 de 14 de junio de 1978. La más brillante y conocida opinión de la desconstitucionalización de la forma de Estado es la de Pedro CRUZ VILLALÓN, "La estructura del Estado o la curiosidad del jurista persan, Revista de la Facultad de Derecho de la Universidad Complutense, núm. 4, Monográfico, 1981, págs. 5363, ahora en La curiosidad del jurista persa y otros estudios sobre la Constitución, CEPC, Madrid, 1999, págs. 381-394. EI ejemplo más próximo que tengo de la tesis sobre el compromiso apócrifo de los constitucionales, que ahora matizo, es un reciente trabajo mío: Agustín Ruiz Robledo, La formación de la Comunidad Autónoma de Andalucía en sus documentos, Comares, Granada, 2003, pág. XXXIV.

La expresión Constitución efectivamente vigente la tomo de Temistocle MArtines, Diritto Costituzionale, 8.0 Ed., Giuffrè, Milán, 1994, pág. 259. La referencia a Emilio ATTARD es por su La Constitución por dentro, Argos Vergara, Barcelona, 1983, págs. 74 y ss. Para la opinión de Pérez Royo sobre el entendimiento alternativo en el año 1978 de los artículos 146 y 152 vid. Javier Pérez RoYo, Las fuentes del Derecho, Tecnos, Madrid, 1984, pág. 136. Sobre el programa electoral del PSOE en 1977, vid. Andrés DE BLAS BUERRERO, «EI problema nacional regional en los programas del PSOE y del PCE», REP, núm. 4, 
julio-agosto 1978 , págs. $155-170$. Por toda la doctrina que reconoce que el principal objetivo del proceso constituyente era resolver el "problema regional" planteado en los dos últimos siglos por las "comunidades periféricas vasca y catalana", vid. Luis LóPEz GUERRA, "Modelo abierto y hecho diferencial", RVAP, núm. 47 (III), 1987, pág 100 y ss.

\section{La configuración del modelo: Hacia la homogeneidad}

Los datos sobre la entrada en el Registro del Congreso de los proyectos de los Estatutos catalán y vasco el 29 de diciembre de 1979 los he tomado de El País del 30 de diciembre de 1978. La idea del Estatuto no como un pacto estable y definitivo sino como un avance hacia otras metas, se puede apreciar en la crónica periodística que reflejo la ratificación del proyecto del Estatuto que hizo la Asamblea de Parlamentarios Vasc el 20 de marzo de 1978. Así, por ejemplo, El País del dia siguiente decía:

«Xabier Arzallus, portavoz del PNV, recordó que aunque su partido no votó afirmativamente la Constitución, sí se comprometió, sin embargo, a acatarla como cauce de su actuación política. Al referirse al Estatuto de Autonomía vasco aprobado por la Asamblea, Arzallus afirmó: "Del mismo modo que la Constitución es un texto abierto como lo demuestra el artículo 150, relativo a las materias de titularidad estatal susceptibles de ser transferidas a los organismos autonómicos, también lo es el proyecto de Estatuto que defendemos, cuya disposición adicional deja la puerta abierta hacia futuras ampliaciones de nivel de autogobierno ahora planteado" ".

Sobre el Pacto del 4 de diciembre de 1978 firmado por todos los partidos andaluces (los tres parlamentarios de entonces y ocho extraparlamentarios) vid. Manuel HIJANO deL Rio y Manuel RuIz RoMERO, El pacto autonómico de Antequera, IAAP, Sevilla, 1997. El proceso autonómico andaluz lo he expuesto con más detenimiento que aquí en mi estudio preliminar a La formación de la Comunidad Autónoma de Andalucía en sus documentos, cit. Lo hace con mayor exhaustividad y gran tino, Fermín Olvera PORCEL, La emergencia de la Administración Autonómica andaluza (1978-1985), Universidad de Granada, 2003.

El primero en calificar a los pactos autonómicos como una convención constitucional fue Luciano VANDELLI, El ordenamiento español 
de las Comunidades Autónomas, IEAL, Madrid, 1982, pág. 403 y ss; tesis que rápidamente fue acogida por la mayoría de la doctrina, por toda ella, cfr. F. Javier GARCíA ROCA, «El principio de voluntariedad autonómica", $R D P$, núm. 21, primavera de 1984, pág. 123 y ss.

\section{La consolidación del modelo}

Sobre la consolidación del Estado autonómico y los segundos pactos autonómicos cfr. Luis López GUerRA, "La segunda fase de construcción del Estado de las Autonomías (1983-1993)", RVAP, núm. 36, 1993, págs. 69-80. La expresión «Estado jurisdiccional autonómico» es de Manuel Aragón, "Estado jurisdiccional autonómico?", RVAP, núm. 16, 1986, págs. 7-12. Sobre el papel delTC en esta etapa de despliegue autonómico cfr. Pedro CRUz VILLALÓN, "La jurisprudencia del Tribunal Constitucional sobre autonomías territoriales", en Sebastián MARTíN RETORTILLO (coord), Estudios sobre la Constitución española: Homenaje al Profesor Eduardo García de Enterría, Civitas, Madrid, 1991, vol. IV, págs. 3339-3371.

\section{La forma de Estado realmente existente}

El término "federalismo asimétrico" -en su origen puramente sociológico - se debe a Charles D. TARLTON, en «Symmetry and asymmetry as elements of federalism: a theoretical speculation", The Journal of Politics, vol. 27, 1965, págs. 861-874.

Sobre las razones para calificar al Estado autonómico como un Estado federal, que no acabo de compartir, cfr., por toda la doctrina, Eliseo AJA, El Estado autonómico. Federalismo y hechos diferenciales, 20. ${ }^{\mathrm{a}}$ ed., Alianza, Madrid, 2003.

Sobre el sistema de financiación cfr. Manuel Medina Guerrero, La incidencia del sistema de financiación en el ejercicio de las competencias de las Comunidades Autónomas, CEC, Madrid, 1993. Sobre las etapas del sistema de financiación, cfr. Antoni CASTELLS, "Balance y perspectivas de la financiación autonómica», en Francesc PAU I VALL (coord.), El futuro del Estado autonómico. VII Jornadas de la Asociación Española de Letrados de Parlamentos, Aranzadi, Pamplona, 2001, págs. 151-163. 


\section{Mínimo balance y proyección para el futuro}

El libro de Eliseo AJA, ya citado, es fundamental para conocer las posibilidades - y las necesidades - de reforma para consolidar el Estado autonómico. Otro balance interesante del Estado autonómico lo ofrece Francesc PAU I VALL (coord.), El futuro del Estado autonómico: VII Jornadas de la Asociación Española de Letrados de Parlamentos, Aranzadi, Navarra, 2001. Para conocer la opinión catalanista, cfr. Enric ARgulLoL, Desarrollar el autogobierno, Península, Barcelona, 2002. Personalmente me he acercado a la reforma desde una perspectiva andaluza en Agustín Ruiz RoBledo, "El futuro del Estatuto de Autonomía", en VV.AA., Estatuto de Autonomia para Andalucía: debates sobre el ayer, el hoy y el mañana, IAAP, Sevilla, 2001, págs. 79-92. 